\title{
The influence of mylonitic and cataclastic rocks in evaluation of the potential for debris and hyper concentrated flows
}

\author{
L. Longoni \& M. Papini \\ Department of Environmental, Hydraulic, Infrastructures and Surveying \\ Engineering, Milan Polytechnic, Italy
}

\begin{abstract}
In this study we want to evaluate the large amount of debris by analyzing a typical alpine setting and focusing on the role of mylonitic and cataclastic zones as a potential supply area for debris and hyper concentrated flows. The crystal basement of the Southern Alps, and in particular of the Valtellina area, is dominated by metamorphic rocks, faulted by important regional fault-systems. These fault-systems and the related mylonitic and cataclastic rocks may produce erosion-prone weak rock outcrops responsible for a large amount of debris production and, consequently, localized erosion and sediment contribution to the drainage network. We focus on Val Tartano, which is characterized by the presence of extended mylonitic and cataclastic areas and we analyze these geological structures as potential high-productivity sources contributing to the increase of river solid transport. Characterization of streambed sediment from a grain size and grain shape viewpoint is described, and their dependence upon the eroded geological parent materials is discussed.

Keywords: debris flow, fault rocks, cataclasite, milonite, grain size, roundness.
\end{abstract}

\section{Introduction}

Riverbeds in mountain areas are frequently affected by hard to predict hydro geological instabilities. Estimation of sediment volumes and grain sizes contributed from valley slopes to the drainage system through erosion and mass transport processes, as well as localized evolution of weaker zones, is of particular interest. We believe that an improvement over current practice in the 
quantitative analysis of sediment production, availability and supply from the slopes is possible and necessary, particularly when dealing with weaker and more erosion-prone geological structures and their associated rock materials. Sediments volume and clasts shape resulting from geomorphic and hydraulic processes can vary largely, and quantitative estimation for several of the involved variables has proved to be a difficult exercise. Among such problems, to quantitative link processes and supply areas for sediments with their grain size and grain morphology is certainly one of the most intriguing tasks. Characterizing the source areas from a geological and geomorphological viewpoint is fundamental, due to the prominent role played by bedrock lithology, by structural elements related to the tectonic history, and by the thickness and characters of the surface soil layer. The present paper is mainly based on the analysis of a particular type of sediment source frequently found in alpine catchments and suitable to give rise to debris flows: the fault rocks (cataclasite and mylonite). These are heavily fractured and brecciated rocks produced by tectonic deformations. We believe that bands of these rocks, which have been observed to occur with widely variable thicknesses, may represent continuous sources of sediments. Of course, the spatial arrangement, spacing and thickness of these rock bands affected by brittle deformation, as well as their attitude respective to the facing and slope of the valley sides control the activity and debris production taking place at these rocks. Since only surface quaternary deposits and talus slopes debris productivity are usually considered as sources by current methods, there is a need for a quantitative assessment of the contribution from erosion of cataclasite and mylonite to the overall sediment productivity. We focus on the Val Tartano catchment, this valley is particularly suited a site for such investigations, given the abundance and frequent occurrence of heavily tectonized areas with cataclasites and mylonites and the easy access to a full spectrum of geometric relations between slope and structures. Furthermore analogous morphologies can be observed at various scales and evolutive stages. Fieldwork being carried out by Politecnico di Milano is aimed at recognizing and surveying those parameters fundamental to the assessment of concentrated brittle bedrock deformation areas as potential sediment sources for debris flows or overall solid transport.

\section{Fault rocks as potential sediment sources}

Recognition, characterization and investigation of weak rocks is very important to evaluate instability. Weak rocks lay in between soils and properly said rocks. They are stronger and more brittle than soils; at the same time, weak rocks behave in a more plastic way than hard rocks, show higher compressibility and are more affected by a change in the stress field acting on them. In this study we consider fault rocks as weak rocks which are related to faults and to localized heavy fracturation zones, whose "weakness" is a direct consequence of the heavy jointing produced by tectonic stresses. Faults can usually represent important weakness zones, because of the fracturation and grinding of rock along the fault 
surface and the fracturation of the surrounding rocks on both sides of the fault surface tends to gradually decrease as the distance from the fault itself increases. Rock fragments and fault breccias may then be cemented up to various extents by subsequent crystallization from circulating mineralizing solutions, but these rocks will generally still have poor mechanical properties. Fault rocks have long been considered as a type of metamorphic rocks produced by cataclastic metamorphism (or dynamic metamorphism). Fault rocks classification does not have a unitary character yet, and most definitions differ more or less depending on the main scientific domains of the various Authors. In 1977 e.g. Sibson [9] defined the term "fault rock" as describing those rocks which are formed at various depths (from deep to shallow) in the crust as a result of shear stresses, combining in this definition both the genetic mechanism and its textural features. He proposed a classification based on the size, type and arrangement of clasts, which control important mechanical properties such as cohesion. Sibson [9] classification is shown in Table 1. The role of fault rocks play in determining slope instability is long known. In most alpine areas the existence of significant portions of weak rocks linked to important tectonic lines is actually among the main causes of several rock landslides.

Table 1: $\quad$ Classification of fault rocks (Sibson [9]).

\begin{tabular}{|c|c|c|c|c|c|c|c|}
\hline \multirow{3}{*}{ 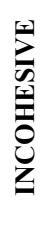 } & & \multicolumn{2}{|c|}{ Random fabric } & \multicolumn{2}{|l|}{ Foliated } & & \\
\hline & & \multicolumn{2}{|c|}{$\begin{array}{l}\text { Fault Breccia (visible } \\
\text { gments }>30 \% \text { rock mass) }\end{array}$} & & & & \\
\hline & & \multicolumn{2}{|c|}{$\begin{array}{c}\text { Fault Gouge (visible } \\
\text { fragments }<30 \% \text { rock mass) }\end{array}$} & & & & \\
\hline \multirow{6}{*}{ 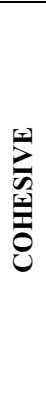 } & \multirow{6}{*}{ 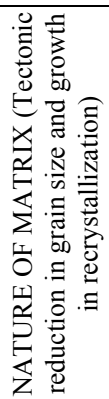 } & \multicolumn{4}{|c|}{ Crush breccia (fragm $>0.5 \mathrm{~cm} \mathrm{ca}$.) } & \multirow{3}{*}{$\frac{i}{2}$} & \\
\hline & & \multicolumn{4}{|c|}{ Fine crush breccia $(0.1 \mathrm{~cm}<$ fragm $<0.5 \mathrm{~cm})$} & & \\
\hline & & \multicolumn{4}{|c|}{ Crush microbreccia $($ fragm $<0.1 \mathrm{~cm})$} & & \\
\hline & & protocaclasite & \multirow{3}{*}{ 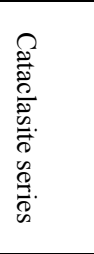 } & protomylonite & \multirow{3}{*}{ 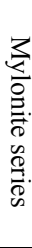 } & 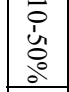 & 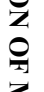 \\
\hline & & cataclasite & & mylonite & & $\overbrace{0}^{\circ}$ ù & \\
\hline & & ultracataclasite & & ultramilonite & & 8 & \\
\hline
\end{tabular}

Far less investigated is the link between these rocks and the subsequent erosion processes taking place at the surface and which are oftentimes responsible of hazardous or destructive events, ranging from high solid transport in the drainage network up to extreme phenomena such as debris flows. In the following we will draw an estimate of the role played by these rocks in supplying material which will be mobilized from the slope down to the drainage channels. 


\section{Evolution state and scale effect of cataclastic area}

When discussing the role of fault zones as sediment sources, we do not only include the relatively small volumes of extremely deformed material on the fault surface, but also the much wider cataclastic area which will be affected by erosion during and in consequence of the geomorphic evolution of those fault rocks.

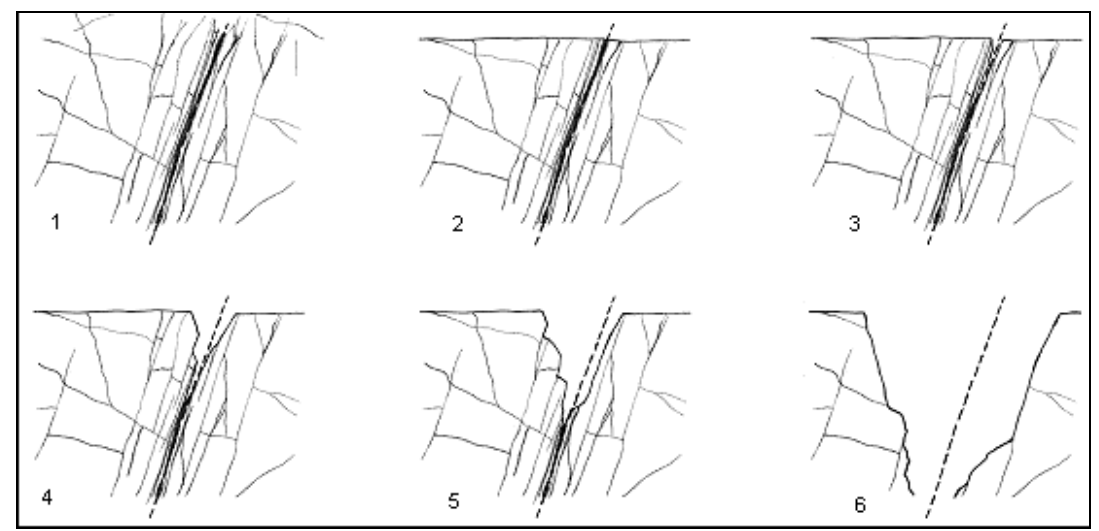

Figure 1: Evolution of fault zone.

In Fig. 1 we consider a fault in the bedrock (1) with its associated lateral bands of rock relatively more and more fractured toward the actual displacement surface, where fine and loose gauge is present. Erosion starts as the rock is exposed at the surface (2) and the gauge is readily washed out of the fault zone (3). Lack of support allow the aperture of existent fractures to widen in the tightly jointed rock on both sides of the fault, easing weathering processes, lowering stability and ultimately giving rise to a first small drainage channel morphology (4). As it draws progressively larger amounts of water in the channel, whose weak rock walls are easily eroded (5). By this stage, further degradation processes have also started, due to the presence of the two high and steep rock faces, and the morphological evolution will tend to completely remove the whole rock volume which had a higher fracturation then the surrounding country bedrock, leaving this small valley running parallel to the strike of the fault. Debris and sediments, whose production must be expected to be particularly abundant, will start to accumulate as soon as the morphologic and hydraulic conditions evolve toward the last stage (6), when the fault will be generally buried below the sediments supplied by erosion acting upstream, where the geomorphologic evolution of the fault area has not yet reached the sixth stage. The erosion and sediment production potential of fault areas is tightly connected to the type of fault rock (cataclasite or mylonite), mineralogical and micro structural characters: in the example discussed above the weakness of the rock mass in the fault area was due to the progressively higher fracturation, up to 
the extreme grinding of the gauge material. This can be the case of most faults where grain-reducing cataclastic processes were active. From the point of view of erosion, the opposite scenery is for mylonite where the rock has accommodated even large strains with a ductile behavior. In this second case, the path to erosion is slower and not as straightforward. A constant feature of mylonites is their foliated texture and is common to observe how weathering takes advantage of it in affecting these fault rocks. Development times of the final weakness of the fault areas, which is required in order for erosion to remove a significant amount of material, are hence controlled by the rate of alteration of the particular lithology. Alteration, in spite of not being a necessary premise for erosion to start in the cataclasite case formerly described, is nonetheless always active. This is important because, given the usually much higher rate of debris production, cataclastic fault areas can become quite excavated before weathering proceeds enough to effectively weaken the rock mass, thus giving rise after some time to a renewed instability phase. We can summarize the implications of fault rock type vs. erosion by noting that cataclasites are inherently easily eroded, while mylonites must go through the intermediate step of weathering before being able to be effectively dismantled by surface erosion processes. Geometric shape scale-independence over several orders of magnitudes is a common feature of most geological structures, faults and fractures being remarkable but not unique examples. Fig. 2 illustrates this concept by shows the very same sketch of Fig. 1 and comparison-scales it against objects of known sizes: each one of the resulting geological settings is perfectly likely to represent a natural, real world situation. This is a fundamental argument supporting the importance that fault areas have as sediment sources, from outcrop up to catchments scales.

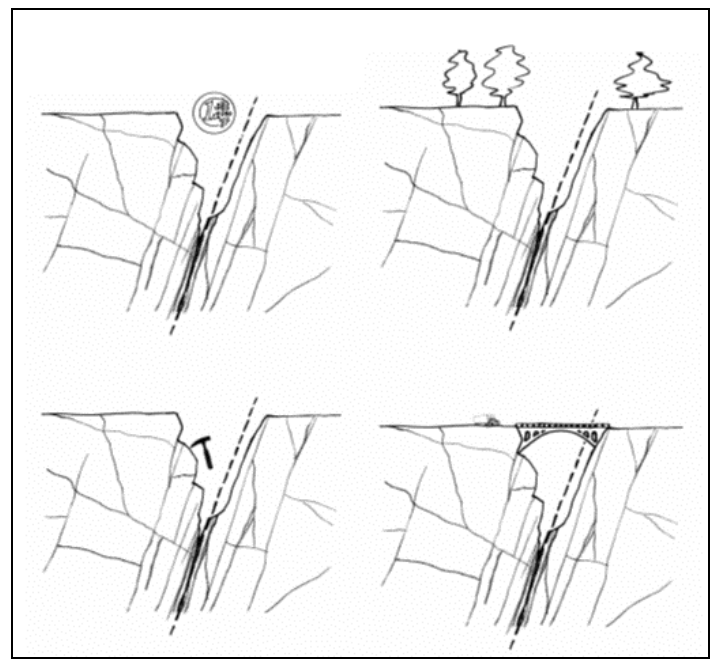

Figure 2: Scale comparison. 


\section{Fault rocks in Val Tartano}

We selected Val Tartano as a case study where to develop the concepts expressed above through further field surveys and data analysis. This valley is located on the southern side of Valtellina and its bedrock belongs to the Gneiss di Morbegno Formation, in the crystalline basement of the Southern Alps structural domain. The foliation of these biotite gneisses has a fairly constant E-W strike and it dips northward with an inclination of $40^{\circ}$ to $90^{\circ}$. Two nearly vertical fault systems intersect the bedrock with NE-SW and NW-SE strikes. Bands of catalastic rocks and very thin (a few cm-thick) mylonites are commonly associated to the NE-SW faults, while NW-SE faults often have a thickness of some meters and well developed mylonites in the most sheared parts. Surrounding these mylonites are cataclastic bands of limited thickness characterized by poorly cemented coarse breccias. Foliation-parallel weak rocks are found in the surveyed area which affect even larger volumes and appear to be related with the said tectonic lines. Such schistosity-related weak rock bands are usually thicker than a few meters and they are characterized by a roughly symmetrical association of fault breccias in the central part. We refer to the study of Agostoni and Papini, [2] for the location of the main tectonic lines and related weak rocks in Val Tartano. By analyzing the role played by the presence and location of these weak areas it appears that they are responsible for rock slopes instabilities: landslide and also solid transport. Most debris accumulations in hollows are clearly supplied by meteorological events which need not to be of exceptional intensity. This can be commonly seen at outcrops of schistosityparallel weak rock bands. In these areas the schistosity lays roughly parallel to the general strike of the NW-SE fault system, so that the tectonization is particularly intense as a consequence of fracturation related both to the highangle fault system and to the schistosity-parallel cataclastic bands. Throughout the whole catchment the higher debris productivity is related to such zones, whereas at areas of E-W foliation strike and NW-SE high-angle faults the debris production and thus the contribution to the drainage network is reduced. This may be likely related to the larger presence of properly said mylonites in this setting. A different situation can be observed for weak tectonized rocks connected to the NE-SW faults, where mylonites are very subordinated volumetrically to wide cataclastic zones which contribute a sensible debris production (but smaller than in the valleys listed above). Furthermore, since no coincidence between foliation and fault systems exist, this debris production is likely to derive mainly from weak rocks at the fault zones themselves, without significant contribution by the foliation-parallel cataclasites. Because of this, during the first stage of our investigations we concentrated on the solid contribution from the high angle faults. Weak rocks in the area have been mapped and their geomechanical properties evaluated by means of in situ tests.

\subsection{Evaluation of grain size and roundness}

This research is aimed at analyzing the debris source areas and to classify them according to grain size distribution and available volume connected with the 
evolution of fault zone, the presence of different fault rocks (cataclasite or mylonite), as well as a scale comparison. At this stage we considered several valleys characterized by the same bedrock lithology and tectonic history and similar scale but with different evolution state. Here we presented two prototype cases: zone 1 and zone 2 (table 2).

Table 2: $\quad$ Zone I and Zone II.

\begin{tabular}{|c|c|c|}
\hline & zone 1 & Zone 2 \\
\hline Scale effect & About 50 meters & About 10 meters \\
\hline Fault rocks & $\begin{array}{c}\text { The zone } 1 \text { is characterized by } \\
\text { the presence of mylonitic and } \\
\text { cataclastic rocks. The erosion } \\
\text { takes place in cataclastic rocks. }\end{array}$ & $\begin{array}{c}\text { The zone } 2 \text { is } \\
\text { characterized by the } \\
\text { presence of cataclastic } \\
\text { rocks. }\end{array}$ \\
\hline Evolution state & The last evolution stage (5 or 6$)$ & $\begin{array}{c}\text { the medium evolution } \\
\text { stage (4) }\end{array}$ \\
\hline
\end{tabular}

In this first phase we only considered the grain size distribution and the roundness of blocks. In a second step we will consider the use of new technology instruments to estimate the volume of sediments and the recharge-time of this potential debris and flows areas. The methodology used to estimate the grain size distribution of this gravel river beds is the numerical method. We also estimated grains roundness. As roundness we mean the degree of smoothness or sharpness of the surface of clasts. It's usually measured with reference to a comparative chart (Powers, 1953, one of the most commonly used [8]). Granulometric curves built following the numeral method refer to diameter frequencies, as opposed to the weight fractions estimated by the use of sieves. This method is based on counting the number of particles belonging to the various grain sizes: the particle lying exactly at each of the grid nodes of the instrument is measured for its minimum and maximum diameters and data is plotted as a frequency histogram for the various grain size classes (Fig. 3 - the first histogram for zone I and the second one for zone II). Data plotting and fitting of analytical distributions to data has been performed using the BestFit 4.5 software following the usual statistical method. The first analysis deals with grain sizes at the two locations detailed below. In the application of the numeral method the finest grain sizes, which could not be easily measured, is not considered. The larger boulders present (reaching size even in excess of a few cubic meters) has similarly been excluded, since our target was on that fraction of the riverbed sediments which can be mobilized with some frequency, i.e. not only during events of exceptional magnitude. Figures 3 shows the grain size distribution as probability histograms at the two example areas. A substantial similarity can be observed both in the two diagrams and in the geological setting surveyed, with similar parent rocks and cataclastic structures.

Since both the finest and coarser tails of the granulometric curve have been omitted from further analysis, it is important to report that at zone 1, the most developed from the erosion viewpoint, the relative amount of these extreme grain sizes are much more important than as zone 2 . Roundness of clasts is also 
useful in depicting a clear picture of the difference between the two sites. Results of visual roundness assessment are shown in Fig. 4 (the first histogram for zone I and the second one for zone II). Roundness has been rated over a scale where 1 corresponds to low roundness and 6 to high roundness. In the small valley, where only cataclasite is present and the erosion-related morphology is less developed, the degree of roundness is lower. As can be seen from comparison of the histograms of the estimated roundness (Fig. 4) the distributions are different, particularly in their tails: the first one (referring to the more developed site) features a tail on the more-rounded side, while at the second site the opposite is true, with a tail showing the presence of a fraction of clasts with lower roundness and less easily mobilized.
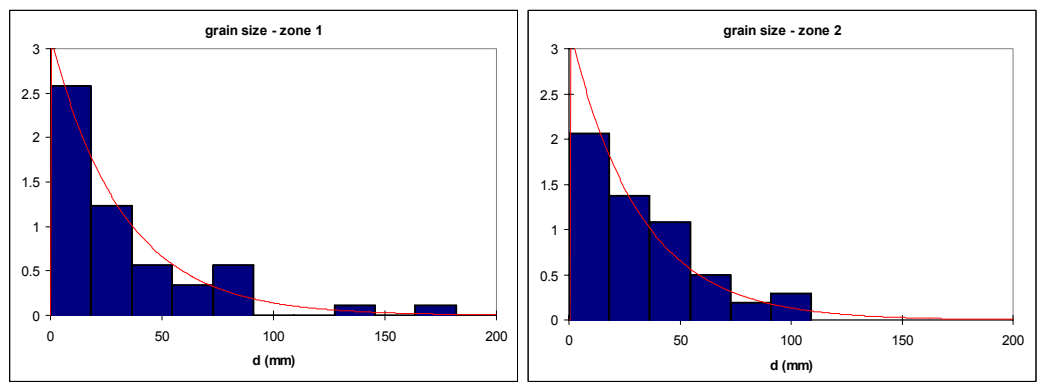

Figure 3: $\quad$ Grain size zone I and II.
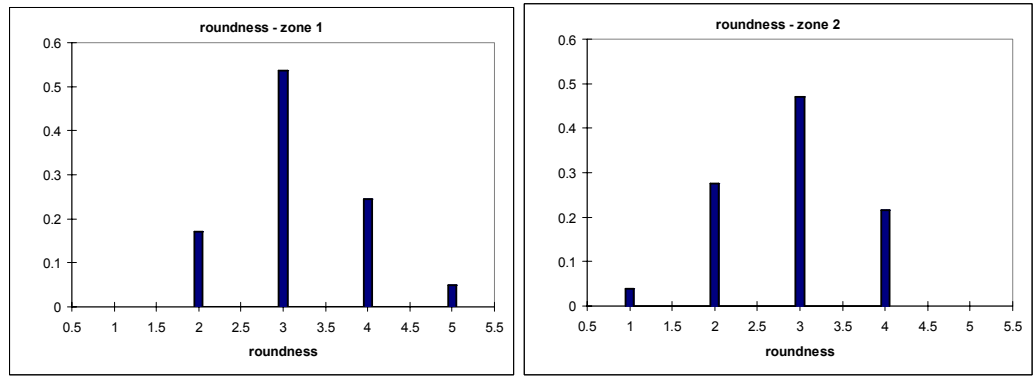

Figure 4: $\quad$ Roundness zone I and II.

We can summarize our results as follows, again with reference to the two examples described above in details. Source areas with cataclastic bands of similar characteristics show substantially similar grain sizes, when excluding the two extremes of very large and fine grain sizes, i.e. in the millimeters to 1 meters range. On the contrary, when considering also the coarser sizes, what is usually found is that the higher development of the erosion morphology corresponds to a substantial presence of very coarse material (e.g., site 1). This is likely to be due to the higher energy available to mobilize such large clasts during extreme events in larger channels with comparison to less developed morphologies, as well as to 
scale factors related to the original size of these rock boulders themselves. Indeed, having been produced by dismantling of comparatively outer parts of the cataclastic bands, where fractures spacing is lower, these late productivity is likely to supply coarse material to the stream bed. At our example site 1 the affected cataclastic area is tens of meters wide, against the few meters width of the involved area at site 2 , where the presence of $1-2 \mathrm{~m}$ sized material is observed only sporadically, over few tens of meters, due to local causes. By analyzing roundness we can conclude that a clear result is apparent: higher evolution corresponds to higher roundness. Thus, in Val Tartano tectonic-related cataclastic zones without coincidence of the schistosity-parallel cataclasites represent a debris source for the streambeds. They contribute material with similar grain sizes whose abundance is in direct relation with the stage of development of erosion. Grain roundness, when compared to grain sizes, is much more sensible a measure of the development of erosion morphology, and is an important parameter in the evaluation of solid transport.

\section{Final consideration and future}

Solid transport and evaluation of potentially debris flows-affected areas is still a developing research field. In order to ever increase the accuracy and precision of sediment characterization with reference to contributions from the valley slopes, some field laboratories have been activated which also allow testing new instruments and their suitability to improve the data collection.

At our Institute the investigations are being carried out in several steps:

$>$ Selection of a suitable area where contribution from erosion of weak rocks is significant

$>$ Catchments analysis from a structural geology viewpoint

$>$ Grouping of debris source areas according to their scale and erosive evolution stage

$>$ Grain size and roundness evaluation

$>$ Evaluation of laser scanning, ground and satellite based radar interferometers.

$>$ Mobilized volumes estimation following transport events by laser scanning

$>$ Evaluation of the feasibility to extract grain size information from laser scanning data, at least for the coarser material.

The table 3 better details some of these technological applications. From these preliminary results it can be seen that structural geology analysis of Val Tartano allowed locating weak areas (milonites and cataclasites), recognizing a scale effect and the relevance of the morphological evolution stage in terms of erosion. This in turn enables answering from a firmer ground to the data needs of risk assessment, hydraulic structures design, and so on. By the end of the investigations related to this project the integration of manually and instrumentally field surveyed data with previously acquired structural geology knowledge of the area. Generalization and validation of the results will then carried out at other catchments and evaluating the effects of different lithologies. 
Table 3: Technological application.

\begin{tabular}{|c|c|}
\hline $\begin{array}{c}\text { Laser scanner } \\
\text { TLS }\end{array}$ & $\begin{array}{c}\text { Monitoring of the most critical areas in terms of hydro } \\
\text { geological instability. By superimposing subsequent point } \\
\text { clouds, the effects of sediment mobilization can be observed. } \\
\text { Attempts are being carried out to evaluate the feasibility of } \\
\text { extracting grain size information }\end{array}$ \\
\hline $\begin{array}{c}\text { satellite based } \\
\text { radar } \\
\text { interferometer }\end{array}$ & $\begin{array}{c}\text { Catchments-scale considerations over a large area in order to } \\
\text { spot the most critical areas. It is possible to use this technique } \\
\text { in the exploratory stage to recognize previously undetected } \\
\text { instabilities. Ranking of streams and areas from the viewpoint } \\
\text { of their sediment productivity can be done }\end{array}$ \\
\hline $\begin{array}{c}\text { ground based } \\
\text { radar } \\
\text { interferometer }\end{array}$ & $\begin{array}{r}\text { It allows one to detect the most active areas on a whole } \\
\text { landslide front. It is characterized by a high resolution } \\
\text { automatic monitoring capability. }\end{array}$ \\
\hline
\end{tabular}

\section{References}

[1] AA. VV. 5th international IAEG Congress, Proceeding of the Symposium on Environmental Geotecnica and Problematic Soil and Rocks, 1986.

[2] Agostoni S, Papini M., Influenza delle miloniti sulla stabilità dei versanti della Val Tartano.Le Strade-anno LXXXX, n.1251, 1998.

[3] Allen W. Hatheway, Poorly lithified weak rock.- AEG NEWS July 1990.

[4] Brodie1, Fettes, Harte and Schmid, Towards a unified nomenclature of metamorphic petrology: Structural terms including fault rock terms, Recommendations by the IUGS Subcommission on the Systematics of Metamorphic Rocks. Web version of 30.11.04.

[5] Byerlee, J. 1990. Friction, overpressure and fault normal compression. Geophysical Research Letters, 17, 21092112.

[6] Hoek E., and Bray J., Rock slope engineering, revised third edition, London, 358, 1981.

[7] Imber J, R E Holdsworth, C A Butler, G E Lloyd, Fault-zone weakening processes along the reactivated Outer Hebrides Fault Zone, Scotland, Journal of the Geological Society, 1997.

[8] Powers, M. C., A new roundness scale for sedimentary particles Journal of Sedimentary Petrology, v. 23, 1953, p. 118.

[9] Sibson, R.H. 1977. Fault rocks and fault mechanisms. Journal of the Geological Society, London, 133, 191-213.

[10] Sibson R.H. - Generation of pseudotachylite by ancient seismic faulting, Geophys. J.R. Astron. Soc., 43. 1975.

[11] S. Laws, S. Loew \& E. Eberhardt, Structural make up and geophysical properties of brittle fault zones in the eastern Aar Massif, Switzerland.

[12] Zhag Xian-Gong and Han Wen-Feng, Engineering geological classification of fault rocks, 1986. 